\title{
Anatomical Observation and Morphometric Study of Acetabulum in South Indian Population
}

\author{
M.B. Sai Keerthana ${ }^{1}$ and S. Sangeetha ${ }^{2}$ \\ ${ }^{1}$ Saveetha Dental College, Saveetha institute of Medical and Technical \\ Sciences,(SIMATS) Saveetha University, Chennai - 600077, India. \\ ${ }^{2}$ Lecturer Department of Anatomy Saveetha Dental College, Saveetha \\ institute of Medical and Technical science,(SIMATS) Saveetha University, \\ Chennai - 600077, India.
}

\section{ABSTRACT}

The acetabulum is a cup shaped portion of the hip bone, that articulates to the femoral head of the femur bone. The acetabulum and the femur bone together forms the bony structure of the hip joint. The main function of acetabulum is that it allows us to walk, run and move freely. Fractures are one of the most common problems that are seen in acetabulum. The excess growth of acetabulum causes the femoral head and the acetabular socket to pinch the labrum of acetabulum resulting in excess pain and decreased range of mobility. The treatments of acetabular fractures can be done through non surgical and surgical methods. The aim of the study is to do the anatomical observation and morphometric study of acetabulum in the south indian population. In the present study, 40 dry hip bones were collected from Anatomy Department of Saveetha Dental college and Sri Ramachandra Medical college, out of which 20 hip bones were of males and 20 hip bones were of females which were pre recorded in the department. These hip bones were collected to analyse two parameters, diameter of acetabulum and width of the notch of the acetabulum. The data that was obtained were analysed and standard deviation values were obtained for both the parameters. These values were plotted in the form of bar graphs.This study concludes that the diameter and the notch of acetabulum was found to be greater in males than females.

\section{KEY WORDS: MORPHOMETRIC, ACETABULUM, NOTCH, DIAMETER.}

\section{INTRODUCTION}

The acetabulum is a deep cup shaped structure that encloses the head of the femur at the hip joint. Acetabulum is a combination of three bones of the pelvis- ilium, pibis, ischium. The crescent surface is the superior surface of acetabulum. It is lined with hyaline cartilage and is the

\section{ARTICLE INFORMATION}

*Corresponding Author: sangeethas.sdc@saveetha.com Received 4th Aug 2020 Accepted after revision 29th Sep 2020 Print ISSN: 0974-6455 Online ISSN: 2321-4007 CODEN: BBRCBA

Thomson Reuters ISI Web of Science Clarivate Analytics USA and Crossref Indexed Journal

\section{1) Clarivate}

NAAS Journal Score 2020 (4.31) SJIF: 2020 (7.728)

A Society of Science and Nature Publication,

Bhopal India 2020. All rights reserved.

Online Contents Available at: http//www.bbrc.in/

Doi: http://dx.doi.org/10.21786/bbrc/13.8/199 only part that controls the femoral head. The acetabular fossa is a deep depression in the floor of the acetabulum that is not lined by hyaline cartilage and does not come in contact with the femoral head.

One of the most weight bearing joints of the body is the hip joint. Hence the knowledge of its morphometric and anatomical features of acetabulum is required for complete mechanics of acetabulum (Dhindsa, 2013). The anatomical features of the acetabulum helps during distinguishing of male and female acetabulum. Female acetabulum are usually smaller as compared to male. Diameter of those acetabulum is relatively larger in male than females (Indurjeeth et al., 2019).

Acetabular measurements or dimension is crucial to diagnose various diseases that are related to the hip

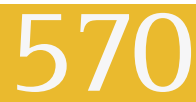


joint which also helps to check the recovery of patients and to access the stability of the hip joint (Sachdeva et al., 2019). These measurements of acetabulum are also helpful during surgical procedures for acetabular reconstruction using materials such as spikes and screws during fixation (Dhindsa, 2013). Therefore acetabulum plays an important role in walking, running or moving freely. It is the major joint for locomotion.

Previously we have done so many morphological and morphometric studies (Krishna and Babu, 2016), (Nandhini et al., 2018), (Subashri and Thenmozhi, 2016), (Keerthana and Thenmozhi, 2016), (Pratha et al., 2016), (Hafeez and Others, 2016), (Choudhari and Thenmozhi, 2016), (Kannan and Thenmozhi, 2016) that led us to conduct study over the past 5 years. This vast research experience has inspired us to do an anatomical observation and morphometric study of acetabulum in the South Indian population.

\section{MATERIAL AND METHODS}

The study was done by using 40 dry human pelvic bones 20 of males and 20 of females from the Anatomy department of Saveetha dental college and Sri Ramachandra medical college Chennai, India. The damaged and fractured bones were not used in the study. The measurements of the pelvic bones were done using a vernier caliper. The values for the two parameters diameter and notch of the acetabulum were measured in millimetre .The data were tabulated, analysed and represented by a bar graph.

\section{RESULTS AND DISCUSSION}

The results obtained from present study shows that the average diameter of acetabulum of male was found to be $48.70 \mathrm{~mm}$ and the average diameter of acetabulum of female was $46.38 \mathrm{~mm}$. The average width of the acetabular notch of male was found to be $25.23 \mathrm{~mm}$ and for female was $23.24 \mathrm{~mm}$. The results clearly show that males have a larger diameter and width of acetabular notch when compared to the females. This difference is due to the variation in their body and developmental structure.

Figure 1: Shows the diameter of the acetabulum measured using a vernier caliper.

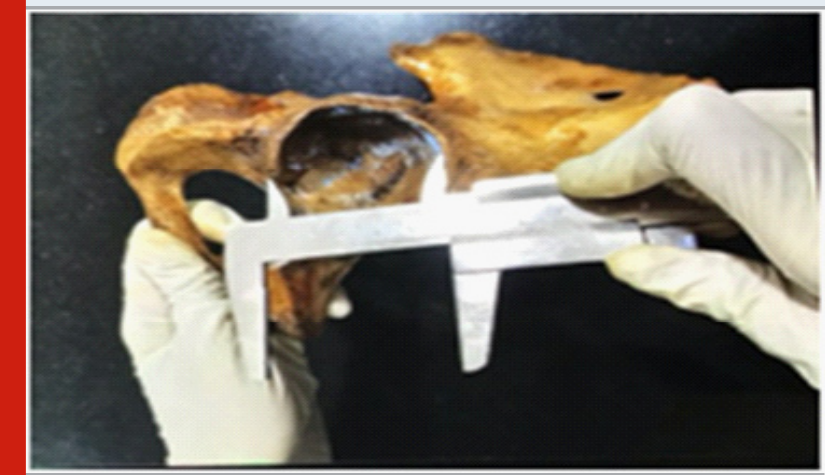

Table 1. Tabular column representing the average/mean values of diameter and width of acetabular notch of males and females.

\begin{tabular}{|l|c|c|}
\hline Average & Male & Female \\
\hline $\begin{array}{l}\text { Maximum diameter } \\
\text { of acetabulum }\end{array}$ & $48.70 \mathrm{~mm}$ & $46.38 \mathrm{~mm}$ \\
\hline $\begin{array}{l}\text { Width of acetabular } \\
\text { Notch }\end{array}$ & $25.23 \mathrm{~mm}$ & $23.24 \mathrm{~mm}$ \\
\hline
\end{tabular}

Figure 2: Bar chart representing the association of gender and maximum diameter of acetabulum. X-axis represents gender and $\mathrm{Y}$ - axis represents maximum diameter of acetabulum in mm.where (Red) "Male" and (blue) "Female". Standard deviation was done for maximum diameter of the acetabulum. Standard deviation of males was $48.7+/-1.53$ for females was $46.4+/-1.08$. Males had larger diameter of acetabulum when compared to females.

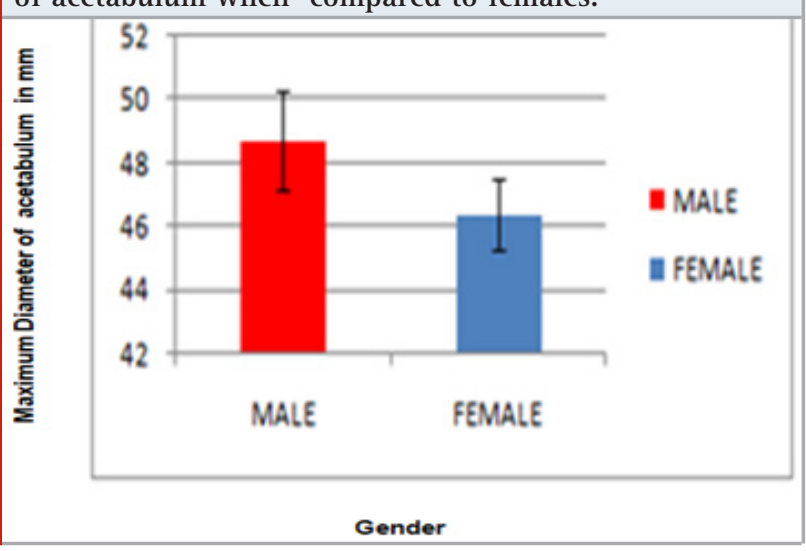

Figure 3: Bar chart representing the association of gender and width of acetabular notch. $\mathrm{X}$ - axis represents the gender and Y-axis represents the width of the acetabular notch in $\mathrm{mm}$,where (red) "Male" and (blue) "Females". Standard deviation was done for width of acetabular notch. Standard deviation for males was 25.23+/- 1.59 and for females was $23.24+/-0.72$. Males had a larger width of acetabular notch when compared to females.

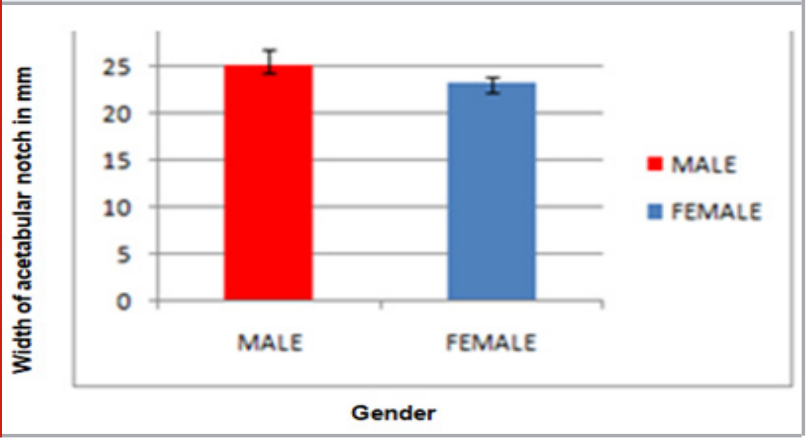

Diameter of acetabulum is the maximum horizontal distance between the margins of the acetabular cavity. Depth of acetabulum is the maximum vertical distance from the edge of the acetabulum of deepest point in 
acetabular cavity. According to the study done by Guru Sharan, the mean diameter of acetabulum was found to be $5.13 \mathrm{~cm}$ on the right side and $5.03 \mathrm{~cm}$ on the left side (Dhindsa, 2013). The depth (mean) was found to be $2.67 \mathrm{~cm}$ on the right side and $2.64 \mathrm{~cm}$ on the left side. The value of volume of acetabulum without labarum was $31.5 \mathrm{~cm} 3$ and with labarum was $41.1 \mathrm{~cm} 3$ of unknown sex were done in the study by Babu. (Babu et al., 2018)

In the study done by Sridharan, they found that all the parameters were relatively larger in male than female. The vertical diameter of the female was $4.8 \mathrm{~cm}$ and male was $5.2 \mathrm{~cm}$. Antero-Posterior diameter of the female was $4.8 \mathrm{~cm}$ and male was $5.2 \mathrm{~cm}$ (Sridharan et al., 2019). The mean diameter of the acetabulum was found $-49 \pm 3.5 \mathrm{~mm}$ right and $48.06 \pm 5.65 \mathrm{~mm}$ left. They also found that $93.3 \%$ of acetabular bone is pointed in anterior and it was lunate shaped posterior end and 1.7\% - bones of both anterior and posterior were pointed (Sreedevi et al., 2017). In the study they found that the depth $11.8 \pm 2.9 \mathrm{~mm}$ - male whose average age was found to be $47.5 \pm 17.5 \mathrm{~mm}$ and for females $55.6 \pm 18.5 \mathrm{~mm}-11.4 \pm 2.5 \mathrm{~mm}$ (Senol, 2017). The results obtained in the study by Nayak were - the diameter of the acetabulum was found to be $4.53 \pm 0.37 \mathrm{~cm}$ - right side and $4.41 \pm 0.39$ left side. Volume $-36.3 \pm 9.84 \mathrm{~m}$ - right side and 30.12 \pm 7.05 left side (Nayak et al., 2017).

The mean weight of the right hip bone was $131.61 \mathrm{gm}$ and on the left hip bone - 119.66gm. The Coxal Index was 74.59 on the right side and 73.32 on the left side (Nayak et al., 2017). They found out that there was more strength of the skeletal element on the right hip bone (Kausar et al., 2018). Based on our study it was found that the average diameter of male was 48.70 and the average diameter of females was 46.38 . The average notch of male was 25.23 and the average notch of females was 23.24. It is seen that a male's pelvis is heart-shaped, whereas the female's pelvis is oval in Shape. -The male pelvis is narrower and taller and the female pelvis is shorter and wider. A wide pelvis usually increases the capacity of the birth canal and by reducing the risk of labor (Warrener et al., 2015). Widening of the hip bones occurs during the female puberty process. The hormone estrogens cause widening of the pelvis during sexual differentiation. This is why females have wider hips that permit childbirth. The male pelvis is generally taller and narrower. It is mainly adapted to fit a more massive and sturdy body architecture (Leong, 2006).

\section{CONCLUSION}

The anatomical parameters of the acetabulum are of immense importance to people who are likely to be orthopaedic surgeons. The present study concluded that the diameter and width of acetabular notch is higher in males than females. Even though the females have broader pelvis than males there was not much difference in the acetabulum. Further study can be done on various parameters of acetabulum for precise clinical correlation. These measurements help to fulfil the need for verifying the validity of various surgical procedures under practise. These parameters are also important for forensic experts.

\section{ACKNOWLEDGEMENTS}

The authors would like to thank the study participants for their participation and kind cooperation throughout the study.

Conflicts of Interest: The authors declare that there were no conflicts of interest in the present study.

\section{REFERENCES}

Babu BV, Babu KY and Mohanraj KG (2018) Morphological and morphometrical analysis of acetabulum with special reference to volume in dry human pelvic bone. Drug Invention Today 10(10).

Choudhari S and Thenmozhi MS (2016) Occurrence and Importance of Posterior Condylar Foramen. Research Journal of Pharmacy and Technology 9(8). A \& V Publications: 1083-1085.

Dhindsa GS (2013) Acetabulum: a morphometric study. Journal of Evolution of Medical and Dental Sciences 2: $657+$.

Hafeez N and Others (2016) Accessory foramen in the middle cranial fossa. Research Journal of Pharmacy and Technology 9(11). A \& V Publications: 1880-1882.

Indurjeeth K, Ishwarkumar S, De Gama BZ, et al. (2019) Morphometry and Morphology of the Acetabulum Within the Black African Population of South Africa. International journal of morphology = Revista internacional de morfologia 37(3): 971-976.

Kannan R and Thenmozhi MS (2016) Morphometric Study of Styloid Process and its Clinical Importance on Eagle's Syndrome. Research Journal of Pharmacy and Technology 9(8). A \& V Publications: 1137-1139. Kausar Z, Bhat GM, Shahdad S, et al. (2018) Morphometry of the adult human dry hip bone in Kashmiri population. International Journal of Research in Medical Sciences. DOI: 10.18203/2320-6012.ijrms20184405.

Keerthana B and Thenmozhi MS (2016) Occurrence of foramen of huschke and its clinical significance. Research Journal of Pharmacy and Technology 9(11). A \&t V Publications: 1835-1836.

Krishna RN and Babu KY (2016) Estimation of stature from physiognomic facial length and morphological facial length. Research Journal of Pharmacy and Technology 9(11): 2071.

Leong A (2006) Sexual dimorphism of the pelvic architecture: a struggling response to destructive and parsimonious forces by natural \&t mate selection. McGill journal of medicine: MJM: an international forum for the advancement of medical sciences by students 9(1): 61-66. 
Nandhini JST, Thaslima Nandhini JS, Yuvaraj Babu K, et al. (2018) Size, Shape, Prominence and Localization of Gerdy's Tubercle in Dry Human Tibial Bones. Research Journal of Pharmacy and Technology. DOI: 10.5958/0974-360x.2018.00663.7.

Nayak G, Professor A, Department of Anatomy, et al. (2017) AN ANATOMICAL STUDY OF DIMENSIONS OF ACETABULUM IN AN EASTERN INDIAN POPULATION. International Journal of Anatomy and Research. DOI: 10.16965/ijar.2017.276.

Pratha AA, Ashwatha Pratha A and Thenmozhi MS (2016) A Study of Occurrence and Morphometric Analysis on Meningo Orbital Foramen. Research Journal of Pharmacy and Technology. DOI: 10.5958/0974360x.2016.00167.0.

Sachdeva K, Singla RK, Kalsey G, et al. (2019) Sex Differences in Morphometry of North Indian AcetabulaForensic and Orthopedic Consideration. National Journal of Clinical Anatomy 08(04). Thieme Medical and Scientific Publishers Private Ltd.: 153-159.
Senol D (2017) Comparison of Diameter and Depth Morphometry in Human Acetabulum in Terms of Age and Gender: A Radiological Study. Journal of Human Anatomy. DOI: 10.23880/jhua-16000109.

Sreedevi G, Professor A, Department of Anatomy, et al. (2017) THE STUDY OF MORPHOLOGY AND MORPHOMETRY OF ACETABULUM ON DRY BONES. International Journal of Anatomy and Research. DOI: 10.16965/ijar.2017.395.

Sridharan I, Professor A, Department of Anatomy, et al. (2019) Morphometric Study of Acetabulum in Adult Dry Human Pelvic Bone. Indian Journal of Anatomy. DOI: 10.21088/ija.2320.0022.8419.7.

Subashri A and Thenmozhi MS (2016) Occipital emissary foramina in human adult skull and their clinical implications. Research Journal of Pharmacy and Technology 9(6). A \& V Publications: 716-718. Warrener AG, Lewton KL, Pontzer H, et al. (2015) A wider pelvis does not increase locomotor cost in humans, with implications for the evolution of childbirth. PloS one 10(3): e0118903. 